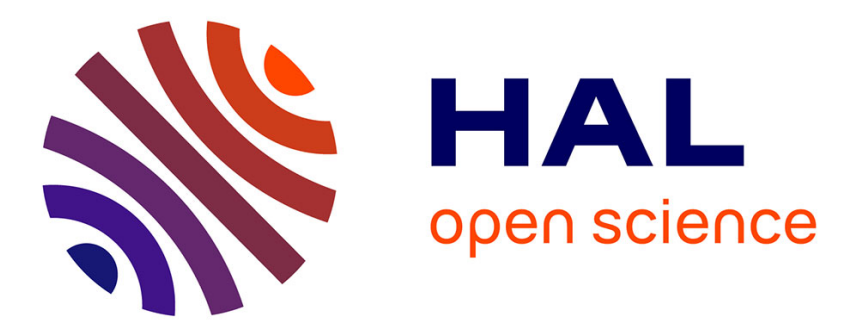

\title{
Incidence and hospitalisation rates of Lyme borreliosis, France, 2004 to 2012.
}

\author{
A Vandenesch, C Turbelin, E Couturier, C Arena, B Jaulhac, E Ferquel, \\ Valérie Choumet, C Saugeon, E Coffinieres, T Blanchon, et al.
}

\section{- To cite this version:}

A Vandenesch, C Turbelin, E Couturier, C Arena, B Jaulhac, et al.. Incidence and hospitalisation rates of Lyme borreliosis, France, 2004 to 2012.. Eurosurveillance, 2014, 10.1016/j.respe.2010.05.003 . pasteur-01453450

\section{HAL Id: pasteur-01453450}

\section{https://hal-pasteur.archives-ouvertes.fr/pasteur-01453450}

Submitted on 22 Jun 2017

HAL is a multi-disciplinary open access archive for the deposit and dissemination of scientific research documents, whether they are published or not. The documents may come from teaching and research institutions in France or abroad, or from public or private research centers.
L'archive ouverte pluridisciplinaire HAL, est destinée au dépôt et à la diffusion de documents scientifiques de niveau recherche, publiés ou non, émanant des établissements d'enseignement et de recherche français ou étrangers, des laboratoires publics ou privés. 


\section{Incidence and hospitalisation rates of Lyme borreliosis, France, 2004 to 2012}

A Vandenesch ${ }^{1,2}$, C Turbelin $^{1,2}$, E Couturier ${ }^{3}$, C Arena $^{1,2}$, B Jaulhac 4,5, E Ferquel $^{6}$, V Choumet $^{6}$, C Saugeon $^{1,2}$, E Coffinieres $^{1,2}$,

T Blanchon (thierry.blanchon@upmc.fr) ${ }^{1,2}$, V Vaillant $^{3}$, T Hanslik $^{2,7,8}$

1. Sorbonne Universités, UPMC Univ Paris 06, UMR_S 1136, F-75013, Paris, France

2. INSERM, UMR_S 1136, F-75013, Paris, France

3. Département des maladies infectieuses (Department of Infectious Diseases), Institut de Veille Sanitaire, Saint-Maurice, France

4. EA 7290, Institut de Bactériologie, Université de Strasbourg, Strasbourg, France

5. Centre National de Reference Borrelia, Centre Hospitalier Universitaire, Strasbourg, France

6. Institut Pasteur, Paris, France

7. UFR des sciences de la santé Simone-Veil, Université Versailles-Saint-Quentin-en-Yvelines, Versailles, France

8. APHP, Service de médecine interne, Hôpital Ambroise Paré, Boulogne-Billancourt, France

Citation style for this article:

Vandenesch A, Turbelin C, Couturier E, Arena C, Jaulhac B, Ferquel E, Choumet V, Saugeon C, Coffinieres E, Blanchon T, Vaillant V, Hanslik T. Incidence and hospitalisation rates of Lyme borreliosis, France, 2004 to 2012. Euro Surveill. 2014;19(34):pii=20883. Available online: http://www.eurosurveillance.org/ ViewArticle.aspx?Articleld $=20883$

Article submitted on 25 July 2013 / published on 28 August 2014

Lyme borreliosis (LB) has become a major concern recently, as trends in several epidemiological studies indicate that there has been an increase in this disease in Europe and America over the last decade. This work provides estimates of LB incidence and hospitalisation rates in France. LB data was obtained from the Sentinelles general practitioner surveillance network (2009-2012) and from the Programme de Médicalisation des Systèmes d'Information (PMSI) data processing centre for hospital discharges (200409). The yearly LB incidence rate averaged 42 per 100,000 inhabitants (95\% confidence interval (CI): 37-48), ranging from 0 to 184 per 100,000 depending on the region. The annual hospitalisation rate due to LB averaged 1.55 per 100,000 inhabitants $(95 \% \mathrm{Cl}$ : 1.42-1.70). Both rates peaked during the summer and fall and had a bimodal age distribution (5-10 years and 50-70 years). Healthcare providers should continue to invest attention to prompt recognition and early therapy for LB, whereas public health strategies should keep promoting use of repellent, daily checks for ticks and their prompt removal.

\section{Introduction}

Lyme borreliosis (LB) is the most common vector-borne disease in the northern hemisphere [1-3]. The economic and social costs of managing the disease represent an important burden on both health services and society $[4,5]$. Several epidemiological studies describe a 2 to 3.6-fold increase in the incidence of this disease over the last decade, in Europe as well as in the United States (US) [6-9].

The American surveillance system, based on notifications of observed cases, has been active since 1991 . In Europe, most countries do not have national monitoring data at their disposal. The Czech Republic and Slovenia are among the few exceptions [1]. In France, the only existing nationwide study is a prospective study conducted by the Sentinelles network with general practitioners (GPs) from 1999 to 2000. It estimated the incidence of the disease at 9.4 per 100,000 , with important inter-regional variations [10]. Several regional studies were also conducted, some on highrisk populations (forest workers), others on the general population in high-risk regions. In eastern France, disease incidence was estimated at 200 per 100,000 inhabitants, and at over 500 per 100,000 in certain areas $[11,12]$.

Estimates of the epidemiological characteristics of LB are useful to orient control and prevention measures, as well as to assess their effectiveness. These data are also necessary to elaborate factual risk communication messages provided to the lay public or the media. Since 1984, the Sentinelles network collects, processes, forecasts and dispatches epidemiological data on the activity of GPs in France [13], in real time. In 2009, LB was added to the list of the monitored health indicators.

We analysed the data collected by the Sentinelles network over the first four years of LB surveillance in France (2009-2012). We also analysed the national hospitalisation databases from 2004 to 2009 (the latest available data at the time of writing this paper).

\section{Methods}

\section{Incidence and characteristics of Lyme}

borreliosis cases (2009-2012)

The Sentinelles network GPs notify weekly the cases of LB they identify during consultations to the network's electronic information system. Notifications are made online throughout the year, in a standardised way. Sentinelles GPs make up a representative 
sample of the national GPs, both in terms of practice area and age distribution of their patients [14]. To be reported by GPs, cases had to meet the following definitions as stated in the European Concerted Action on Lyme Borreliosis criteria: (i) presence of an erythema migrans (clinical diagnosis); or (ii) appearance of neurological, articular (arthritis only), cutaneous or cardiac symptoms evocative of Lyme disease, in a patient with positive serology [15].

For each notified case, a standardised questionnaire provided information on the patient's age and sex, the date of diagnosis, a history of tick bite before the consultation (date of bite), presence of asthenia, myalgia, cutaneous manifestations (erythema migrans with a single or numerous lesion(s), lymphocytoma, acrodermatitis (ACA)), neurological manifestations (meningoradiculitis, clinical signs of meningitis, meningoencephalitis, radiculitis, facial paralysis, events related to another cranial nerve), the presence of arthritis (articulation(s) concerned) or cardiac events (atrioventricular block, pericarditis, myocarditis, other) and, when available, the results of cerebrospinal fluid (CSF) analysis and serological tests. Three of the authors (AV, CA, TH) validated the reported cases when they met the adopted case definition. Validation of cases is an ongoing regular activity of the surveillance procedure and involves checking the consistency of data reported in the standardised questionnaire for each reported cases. When needed, GPs are contacted for more information. Cases of meningoradiculitis or unilateral facial paralysis were validated even if CSF fluid analysis had not been done, when they were clinically very suggestive (consensus agreement between three authors, AV, CA and TH) in patients who reported a history of erythema migrans less than two months before the onset of neurological manifestations [16].

Cases reported from 1 January 2009 through 31 December 2012 were analysed. The annual incidence rate was calculated as follows: the average number of cases notified by Sentinelles GPs (adjusted for participation and geographic distribution) was multiplied by the total number of private GPs practicing in France [17]. This product was then divided by the French population [18]. Confidence intervals were estimated under the assumption that the number of reported cases followed a Poisson distribution.

\section{Lyme borreliosis hospitalisations (2004-2009)}

Hospitalisation data were collected by reviewing all hospital discharge reports containing an LB code from 1 January 2004 through 31 December 2009 (the latest available data at the time of writing this paper), all obtained through the Programme de Médicalisation des Systèmes d'Information (PMSI) data processing centre [19]. This database is a national register of all discharges from all short-stay/acute-care hospitals. It collects data described by the physicians who took care of the patients during their hospitalisation, using the International Classification of Diseases, 10th revision
(ICD-10) [20]. We identified all the hospitalisation reports for which a LB code was reported, i.e. M01.2* (Lyme arthritis), L90.4 (acrodermatitis) or A69.2 (Lyme disease), either for primary or secondary diagnoses. A hospitalisation was considered compatible with LB and retained in the analyses when the data in the hospital discharge report satisfied one of the following criteria (Table): (i) a hospital discharge report with a code specific for LB diagnosis (ICD-10 codes M01.2* or L90.4), (ii) a hospital discharge report with ICD-10 Code A69.2 in the absence of any other diagnosis, or (iii) a hospital discharge report with ICD-10 Code A69.2 together with one or more associated diagnosis code(s) compatible with LB symptoms (neurological, cardiac, articular and ocular disorders). Hospitalisations were described by age, sex, region of residence of the patient, and types of disorders. Also, seasonality and the mean duration of hospitalisation were presented. To estimate the average annual incidence rate of hospitalisations (national and regional), the number of hospital stays in a given geographical area was divided by the average population in the study period, and then multiplied by $100,000[18]$.

\section{Results}

\section{Incidence and characteristics of Lyme borreliosis cases (2009-2012)}

From 2009 through 2012, GPs of the Sentinelles network reported 441 cases of Lyme borreliosis, 110 of which were not chosen for validation because they did not meet the criteria. These were mostly late manifestations without serological confirmation $(n=42)$, tick bites without any clinical event $(n=25)$, insufficiently completed questionnaires $(n=19)$, positive serology without any associated clinical event $(n=8)$, diagnosis errors later confirmed by the GP $(n=7)$, data capture errors $(n=4)$, prevalent but non incident cases $(n=5)$. The remaining 331 cases were validated and analysed.

The estimated yearly LB incidence averaged 26,584 cases (95\% confidence interval (Cl): 23,053-30,115), representing an estimated average incidence rate of 42 per 100,000 national population ( $95 \% \mathrm{Cl}: 37-48)$. This result was stable over the four years of monitoring: 42 per 100,000 inhabitants ( $95 \% \mathrm{Cl}: 30-54$ ) in 2009, 42 per 100,000 (95\% Cl: $32-52)$ in 2010,41 per 100,000 (95\% Cl: $31-51)$ in 2011 and 44 per $100000(95 \% \mathrm{Cl}$ : 32-56) in 2012. Regionally, the average incidence rate ranged from 184 (95\% Cl: 31-356) per 100,000 population in the Limousin region and 157 (95\% Cl: 34-279) in Alsace to $O$ in Nord-Pas-de-Calais and Bourgogne (Figure $1 \mathrm{~A}$ ). The incidence peaked during the months of June to October (Figure 2A).

Women represented $52 \%$ of these 331 cases $(p=0.37)$. The age distribution revealed two peaks, between 5 and 10 years and between 50 and 70 years (Figure 3). A tick bite was reported by $74 \%$ of patients. The average delay between the bite and the date of diagnosis was 28 days, with a median of 10 days. Most reported cases 
TABLE 1

ICD-10 codes of clinical disorders that may be related to Lyme borreliosis

\begin{tabular}{|c|c|}
\hline ICD-10 chapters and group of conditions concerned ${ }^{\mathrm{a}}$ & ICD-10 code concerned \\
\hline \multicolumn{2}{|l|}{ Chapter VI: Diseases of the nervous system } \\
\hline Inflammatory diseases of the central nervous system & Goo-9 \\
\hline Disorders of the trigeminal nerve & $\mathrm{G}_{50} 0.8, \mathrm{G}_{50.9}$ \\
\hline Facial nerve disorders & $G_{51}, G_{51.0}, G_{51.8}, G_{51.9}$ \\
\hline Disorders of other cranial nerves & $\mathrm{G}_{52}, \mathrm{G}_{52.0-3,} \mathrm{G}_{52.7-9}$ \\
\hline Cranial nerve disorders in diseases classified elsewhere & $G_{53}, G_{531}, G_{53}$ \\
\hline Nerve root and plexus disorders & $\mathrm{G}_{54}, \mathrm{G}_{54.0-5}, \mathrm{G}_{54.8-9}$ \\
\hline Other polyneuropathies & G62, G62.8-9 \\
\hline Polyneuropathy in diseases classified elsewhere & G63, G63.0 \\
\hline Other disorders of the peripheral nervous system & G64 \\
\hline \multicolumn{2}{|l|}{ Chapter VII: Diseases of the eye and adnexa } \\
\hline Iridocyclitis & $\mathrm{H}_{2} \mathrm{O}, \mathrm{H} 2 \mathrm{O} .0-1, \mathrm{H} 2 \mathrm{O} .8-9$ \\
\hline Other disorders of iris and ciliary body & $\mathrm{H} 21, \mathrm{H} 21.8-9$ \\
\hline Disorders of iris and ciliary body in diseases classified elsewhere & $\mathrm{H} 22, \mathrm{H} 22.0-1, \mathrm{H} 022.8$ \\
\hline Chorioretinal inflammation & H30, H30.0-9 \\
\hline Other disorders of the choroid & $\mathrm{H}_{31}, \mathrm{H}_{31.8-9}$ \\
\hline Chorioretinal disorders in diseases classified elsewhere & $\mathrm{H}_{32}, \mathrm{H}_{32} 2.0-8$ \\
\hline \multicolumn{2}{|l|}{ Chapter IX: Diseases of the circulatory system } \\
\hline Acute pericarditis & $130,130.0-9$ \\
\hline Pericarditis in diseases classified elsewhere & $132,132.0-8$ \\
\hline Acute myocarditis & $140,140.0-9$ \\
\hline Myocarditis in diseases classified elsewhere & $141,141.0,141.2,141.8$ \\
\hline Cardiomyopathy & $142,142.9$ \\
\hline Cardiomyopathy in diseases classified elsewhere & $143,143.0$ \\
\hline Atrioventricular and left bundle branch block & $144,144.0-7$ \\
\hline Other conduction disorders & $145,145 \cdot 0-9$ \\
\hline Other heart disorders in diseases classified elsewhere & $152,152.0-8$ \\
\hline \multicolumn{2}{|l|}{ Chapter XIII: Diseases of the musculoskeletal system and connective tissue } \\
\hline Arthritis and polyarthritis due to other specified bacterial agents & Moo.8, Moo.80-9 \\
\hline Direct infections of joint in infectious and parasitic diseases classified elsewhere & Mo1, M01.2, M01.20-9, M01.30-9, M01.80-9 \\
\hline Other arthritis & M130-9 \\
\hline Arthropathies in other diseases classified elsewhere & $\mathrm{M}_{14}, \mathrm{M}_{14.8}$ \\
\hline
\end{tabular}

a International Classification of Diseases, 10th Revision [20].

had erythema migrans (93.6\%), with a single lesion in $91 \%$ of cases and multiple lesions in $9 \%$ of cases. Other clinical forms of the disease were reported in a limited number of cases: cutaneous lymphocytoma $(n=4), A C A$ $(n=3)$, arthritis $(n=9)$, neurological disorders $(n=5)$, and one patient presented both arthritis and neurological disorders. For one patient only presenting a neurological form of LB, a lumbar puncture was performed to confirm the diagnosis.

Lyme borreliosis hospitalisations (2004-2009) Among the 14,348 files extracted in France from the PMSI from 2004 through 2009, 5,727 were considered compatible with a diagnosis of Lyme disease, i.e. $40 \%$ of all hospitalisation records with an LB code. Therefore, the estimated average incidence of hospitalisations was 954 per year (Figure 4), which represents an estimated annual average hospitalisation rate over the period of 1.55 per 100,000 inhabitants $(95 \% \mathrm{Cl}$ : $1.42-1.70$ ), ranging from 1.38 to 1.87 . Regional variations of hospitalisation rates were remarkable, ranging from 6.72 per 100,000 inhabitants per year in Alsace, to 0.30 in Corsica (Figure 1B).

These hospitalisations concerned women in $42.2 \%$ of cases (p<0.001). The age distribution revealed two peaks: one between 5 and 10 years and another around the age of 55 years (Figure 5). Reasons for hospitalisation were neurological disorders $(n=2,820)$, LB with no associated diagnosis $(n=1,860)$, arthritis $(n=660)$, cardiac events $(n=304)$, ocular disorders $(n=87)$ and ACA $(n=85)$. The monthly distribution of hospitalisations (month of entry) peaked between June and November (Figure 2B). The average duration of stay was 5.3 days 
Estimated annual regional incidence rates of Lyme borreliosis in general practice (2009-2012) and hospitalisations (20042012), France

A. General practice (2009-2012)

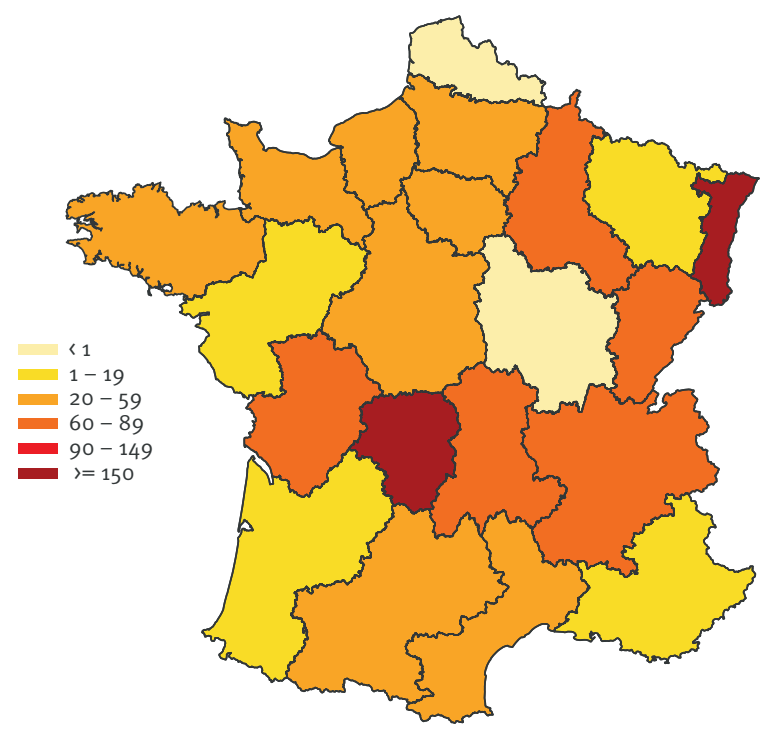

B. Hospitalisations (2004-2009)

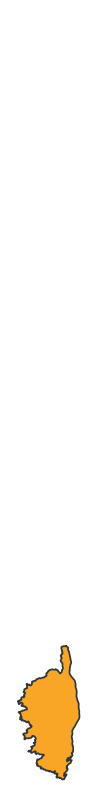

Incidence rates per 100,000 inhabitants.

and varied, according to the LB form, from an average of 3.0 days for hospitalisations coded with an isolated LB code, to 8.3 days for LB associated to cardiac disorders.

\section{Discussion}

Data from the Sentinelles GP network and administrative hospitalisation database allowed for an updated and ongoing description of the epidemiology of LB in France. Although they covered different time periods, there was consistency between the data sources in regard to age distribution, seasonality and spatial distribution. The study confirmed that the incidence was greater in the eastern and central regions of France, increased in summer, and was higher among young children and older adults. It also confirmed that GPs play a major role in diagnosing and treating the early forms of the infection. Even though they were unusual, severe forms made hospitalisation necessary.

On the basis of the 331 cases collected and validated by the Sentinelles network, the LB incidence was estimated at 42 (95\% Cl: 37-48) for 100,000 inhabitants. The actual LB incidence could in fact be higher than this estimate, since patients who did not consult a GP were not covered by this study. There is no published or unpublished information that could help assess the magnitude of this effect. However, nowadays in France, people cannot go directly to a specialist without first consulting a GP. It is therefore likely that the vast majority of patients had been seen by a GP. The incidence rates estimated here can be compared with incidence rates in other European countries, although such comparisons must be interpreted with caution. Indeed, there are differences between countries in the process of data collection. Only some countries use a continuous surveillance system, and case definitions and laboratory confirmation methods vary $[1,9]$. In 2005 , the highest incidence rates of LB in Europe were reported in Slovenia with 206 cases per 100,000 inhabitants, Austria with 135 cases per 100,000 inhabitants and the Netherlands with 103 cases per 100,000 inhabitants [9]. A high yearly incidence rate of LB (131 per 100,000 inhabitants) was also reported in Switzerland between 2008 and 2011 [21]. Incidence measured in Germany in 2006 amounted to 37.3 per 100,000 inhabitants in six of the 16 federal states [8]. In the Czech Republic in 2006 , it was 42.6 per 100,000 , close to the national incidence in France. In Belgium, it was 16 per 100,000 in 2005 [9], whereas the Belgian network of sentinel GP estimated the incidence rate of erythema migrans at 90.2 per 100,000 in 2009 [22]. The incidence rate was below 1 per 100,000 in Italy and Portugal in 2005 [9].

The only earlier available data on French national incidence of LB were provided by a study conducted by the Sentinelles network in 1999 and 2000. It estimated the national incidence rate at 9.4 per 100,000 inhabitants [10]. The higher incidence reported in the present study could suggest that the LB incidence rate has increased in France. However, these incidences must be compared with caution, since different artifacts may have contributed to the higher numbers. Firstly, it has been shown 
Mean monthly incidence rate of Lyme borreliosis in general practice (2009-2012) and number of hospital admissions (2004-2009), France)
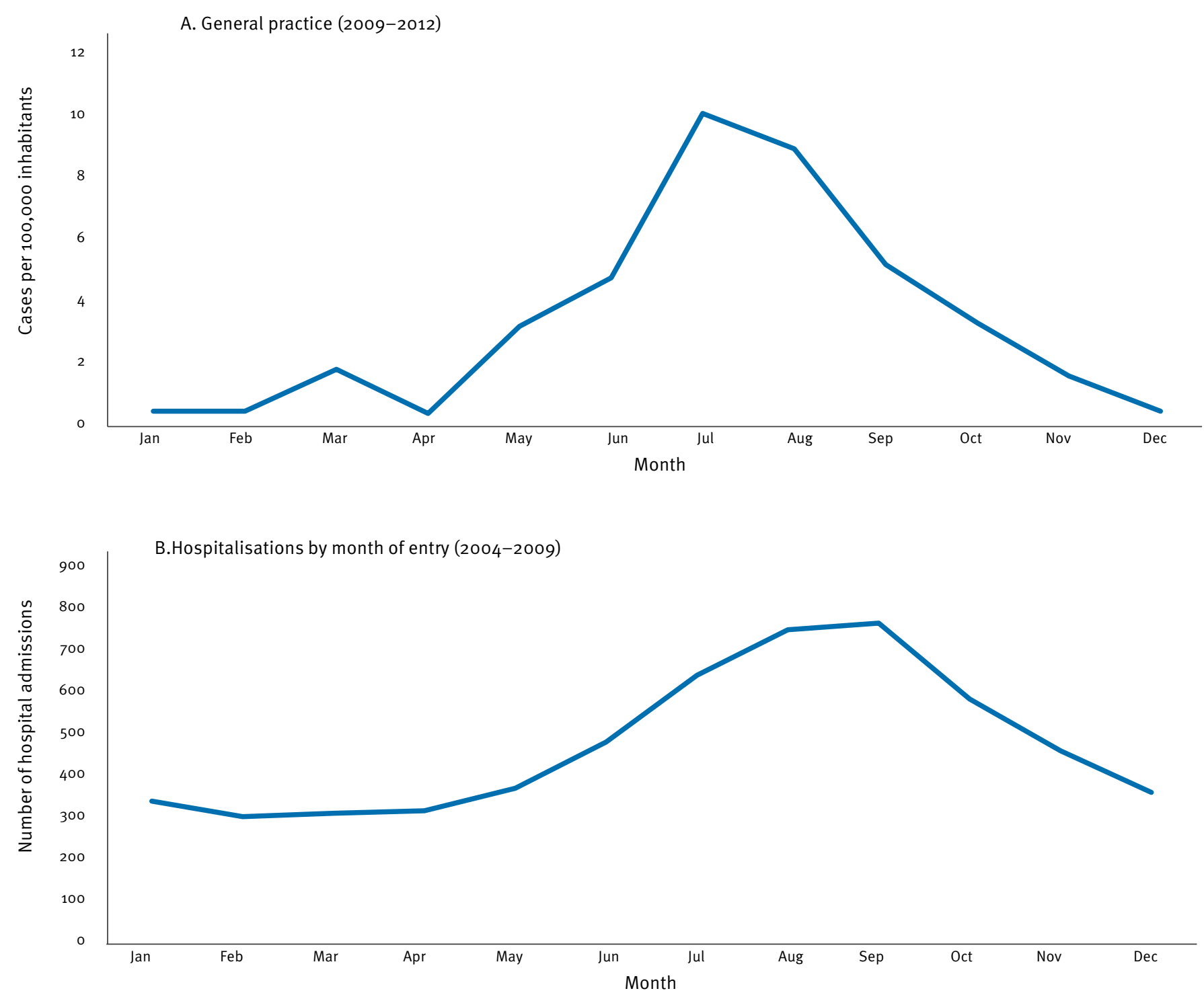

Incidence rates per 100,000 inhabitants.

that the incidence of LB is highly sensitive to changes in surveillance methods [23]. Indeed, the methodology used by Letrilliart et al. in 1999-2000 was different from the one we applied, and probably led to an underestimation of the incidence rate in their study. At the time, data were not collected through a routine systematic and standardised surveillance, as they have been since 2009 . The routine surveillance of the Sentinelles network is based on periodic reports from sentinel physicians (usually weekly reports). Thus, if a physician does not provide report for several weeks, they will not be counted as a participating during those weeks. In the 1999 survey, it was assumed that physicians reported cases actively during the entire study period. Thus, compared to routine surveillance, the number of cases declared in the 1999 study was attributed to an overestimated number of participating GPs, resulting in lower incidence estimates. Secondly, LB today is better known to the public and the GPs than it was in 1999, which may have contributed to the strong increase in estimated LB incidence we report here [6]. Finally, the number of hospitalised cases was stable over the period 2004-2009 and seems incompatible with a four-fold increase in incidence suggested by a comparison of incidence estimates derived from the 1999-2000 study and the 2009-12 surveillance data. The hospital discharge database being a stable system, surveillance bias is unlikely, and the database can therefore provide useful data for trend analyses.

Nevertheless, numerous studies and surveillance data from other European countries and the US showed 


\section{FIGURE 3}

Annual incidence rates of Lyme borreliosis by age group as estimated by the general practitioners' Sentinelles network, France, 2009-2012

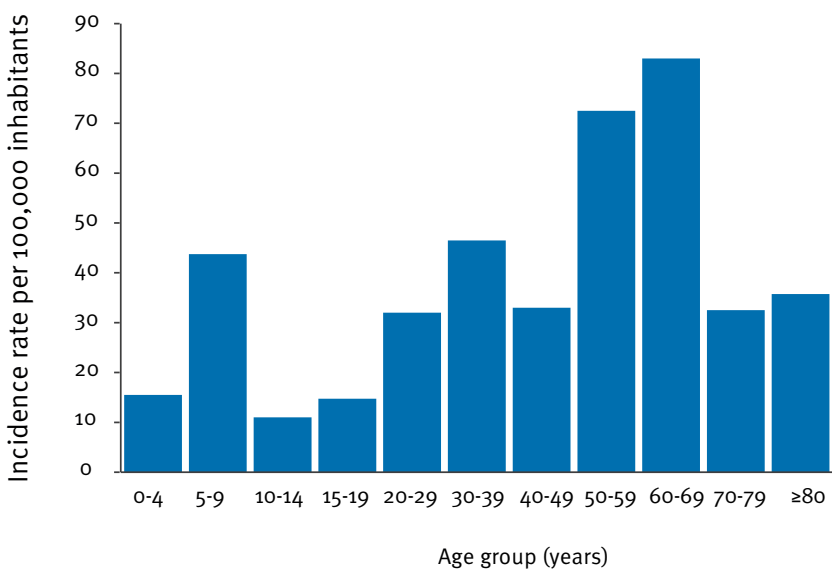

that the LB incidence may indeed have increased over the past few decades. In the US, a continued surveillance system was created in 1991, and the incidence has increased by $101 \%$ since then [6]. In Europe, an increase in LB was observed in several countries [9]. Between 1990 and 2001, the incidence rate in the Czech Republic doubled [1]). In Germany, Fulop et al. describe a 110\% increase between 2001 and 2006 [8]. In the United Kingdom, case numbers have increased 3.6-fold between 2001 and 2011 [24]. In addition, some factors not related to surveillance artifacts may have contributed to an actual incidence increase, such as climate changes $[25,26]$, increases in the population of wild animals hosting ticks, modifications in agricultural and forest landscapes that can lead to a higher density of tick populations [1], or reduction in biodiversity that can increase the prevalence of ticks carrying Borellia [27].

Regional incidence rates varied considerably in France, from o per 100,000 inhabitants to 184 per 100,000 . These variations could be explained by participation biases. However, they were the same as those observed in the earlier Sentinelles network study [10] and, more importantly, the regional hospitalisation incidences corroborated the GP surveillance data, as shown by the similar distribution of GP and hospitalisation data in Figure 1. Other published studies confirmed the regional distribution reported here [11]. In the US, incidence also varied among states, from less than 0.01 per 100,000 inhabitants in Montana or Colorado, to 73 per 100,000 in Connecticut [6]. The confirmation of interregional variations is an asset to guide future studies and develop more efficient public health actions.

In $94 \%$ of the cases in France, the infection was diagnosed at the erythema migrans stage. In the US, the proportion of erythema migrans was lower, estimated at $69 \%$ [6]. However, the data collection process in the US included cases reported through laboratorybased surveillance that are more likely to have late manifestations of LB [23]. An earlier study conducted in France with GPs, specialists and hospital practitioners reported a proportion of erythema migrans of $68 \%$ [11]. In Europe, published data varied from $65 \%$ to $95 \%[11,28,29]$. These observations suggest that either the incidence of late Lyme disease forms in general practice in France is underestimated or the incidence of erythema migrans is overdiagnosed. Indeed, the lesion can be confused with other dermatological disorders, and the positive predictive value of an erythema migrans diagnosis made by GPs in France has been estimated at $72 \%$ [30].

There was a marked difference in the sex ratio between outpatients (predominantly female) and inpatients (predominantly male), for which we have no explanation. Sex differences in the risk of contracting tick bites, incidence rates, and clinical picture of erythema migrans have been reported, although the biological, immunological, and sociological mechanisms causing these differences have not been determined [31].

There are limits to the use of data coming from the national hospitalisation statistics, including diagnosis and coding mistakes, unintentional omissions, partial reporting of pre-existing conditions, lack of information about treatments (whether or not patients received an LB-effective antibiotic could help validate the diagnosis), the frequent unavailability of medical history forms to the certifying practitioner or difficulties in determining the initial cause of hospitalisation when several associated pathologies are involved. Indeed, it is possible that the recorded diagnoses were given by physicians who did not base their decision on accepted case definitions. Also, the diseases defined by the ICD-10 codes that we used are not specific for LB, their aetiologies may be numerous and in many cases idiopathic. It has been previously shown that the positive

\section{FIGURE 4}

Lyme borreliosis hospitalisations per year, France, 2004-2009

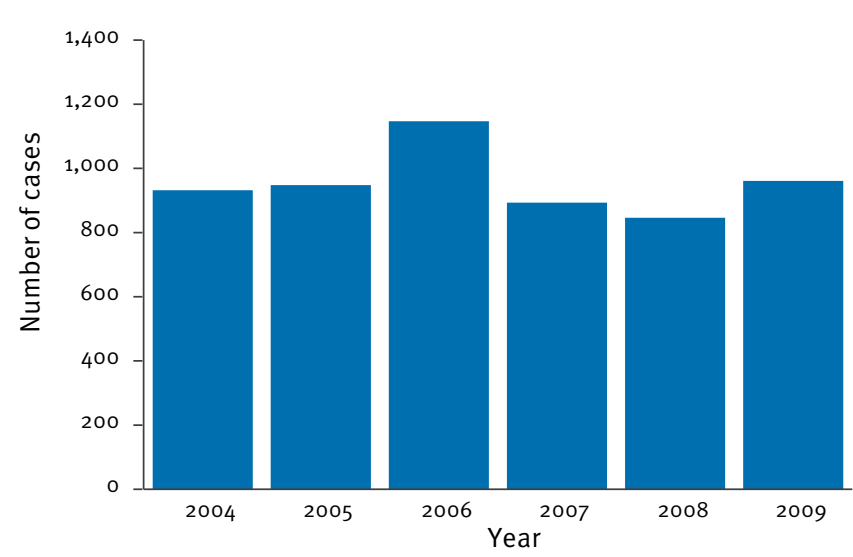




\section{FIGURE 5}

Age-specific distribution of Lyme borreliosis

hospitalisations, France, 2004-2009

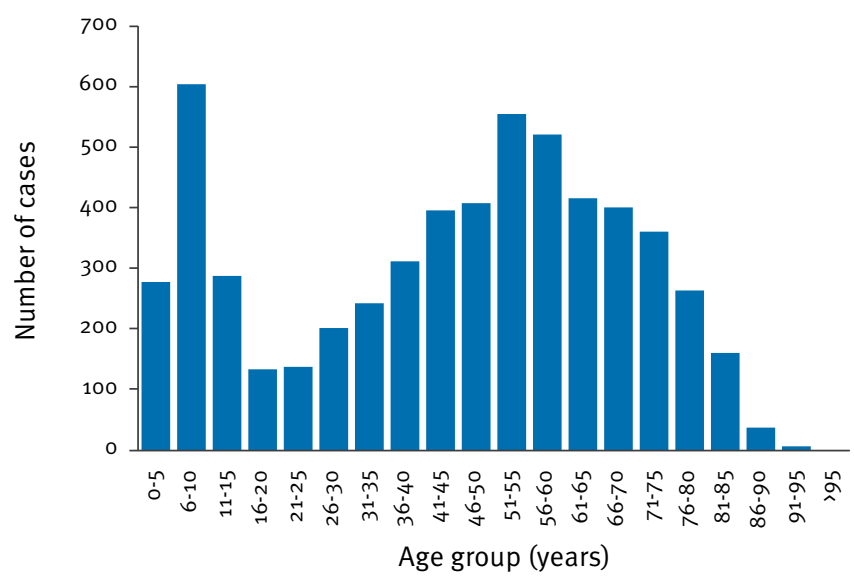

predictive value of the LB code in the PMSI database was $65 \%$ [32]. We therefore considered it necessary to set up a selection process for the reported hospitalisations. In the end, we only kept $40 \%$ of the registered reports. Nevertheless, the predictive value of our case definition could remain low due to the lack of specificity of the retained hospitalisation definitions (related to the complexity of databases such as the PMSI hospitalisation database). Therefore, our study could also overestimate the hospitalisation rates for LB in France. However, the PMSI database proved a useful tool to monitor trends over time, determine the seasonality, determine high-risk regions, and provide details on characteristics of hospitalised patients.

\section{Conclusions}

In conclusion, a countrywide sentinel network and hospitalisation statistics produced epidemiological data that were sustainable and consistent over time and space. They were suitable for following trends and estimating the burden of this disease for which there is significant public concern. Determination of the healthcare burden associated with LB can inform public health policy and enable valid analysis of the efficiency of LB control measures. Furthermore, we believe that this study could help elaborate factual risk communication messages provided to the lay public or the media. Healthcare providers should continue to invest attention into prompt recognition and early, appropriate therapy for LB. Also, public health strategies should keep promoting the use of repellent, daily checks for ticks and their prompt removal, mainly in the age groups, in the regions and during the months with the highest incidences.

\section{Acknowledgements}

The authors wish to thank all the Sentinelles network GPs. This work was funded by the French Institute for Health and Medical Research (INSERM) and the French Institute for Public Health Surveillance (InVS).
Conflict of interest

None declared

Authors' contributions

All authors participated in the conceptualisation and writing of this manuscript. AV and TH designed the research, analysed data and drafted the article; CT, AA, VC and CA analysed data; EC, BJ, EF, CS, EC, VV and TB interpreted the data and revised it critically for important intellectual content

\section{References}

1. Lindgren E, Jaenson TG. Lyme borreliosis in Europe: influence of climate and climate change, epidemiology, ecology and adaptation measures. Geneva: World Health Organization, 2006. Available from: http://www.euro.who.int/_data/assets/ pdf_file/ooo6/96819/E89522.pdf

2. O'Connell S, Granstrom M, Gray JS, Stanek G. Epidemiology of European Lyme borreliosis. Zentralbl Bakteriol. 1998;287(3):229-40.

http://dx.doi.org/10.1016/So934-8840(98)80124-2

3. Stanek G, Wormser GP, Gray J, Strle F. Lyme borreliosis. Lancet. 2012;379(9814):461-73. http://dx.doi.org/10.1016/S0140-6736(11)60103-7

4. Rizzoli A, Hauffe H, Carpi G, Vourc HG, Neteler M, Rosa R. Lyme borreliosis in Europe. Euro Surveill. 2011;16(27):pii=19906.

5. Zhang X, Meltzer MI, Pe-a CA, Hopkins AB, Wroth L, Fix AD. Economic impact of Lyme disease. Emerg Infect Dis. 2006;12(4):653-60. http://dx.doi.org/10.3201/eid1204.050602

6. Bacon RM, Kugeler KJ, Mead PS. Surveillance for Lyme disease--United States, 1992-2006. MMWR Surveill Summ. 2008;57(10):1-9.

7. Bennet L, Halling A, Berglund J. Increased incidence of Lyme borreliosis in southern Sweden following mild winters and during warm, humid summers. Eur J Clin Microbiol Infect Dis. 2006;25(7):426-32.

http://dx.doi.org/10.1007/s10096-006-0167-2

8. Fulop B, Poggensee G. Epidemiological situation of Lyme borreliosis in Germany: surveillance data from six Eastern German States, 2002 to 2006. Parasitol Res. 2008;103 Suppl 1:S117-20.

http://dx.doi.org/10.1007/s00436-008-1060-y

9. Smith R, Takkinen J, Editorial team. Lyme borreliosis: Europewide coordinated surveillance and action needed? Euro Surveill. 2006;11(6):pii=2977.

10. Letrilliart L, Ragon B, Hanslik T, Flahault A. Lyme disease in France: a primary care-based prospective study. Epidemiol Infect. 2005;133(5):935-42. http://dx.doi.org/10.1017/So950268805004413

11. French Institute for Public Health Surveillance (InVS). La maladie de Lyme. Données du réseau de surveillance de la maladie en Alsace, Mars 2001 - Février 2003 [Lyme disease. Data from the Lyme disease surveillance network in Alsace. March 2001-February 2003]. Paris: InVS; 2005 . French. Available from: http://www.invs.sante.fr/publications/2005/ Lyme_alsace/

12. Chapuis JL, Ferquel E, Patey O, Vourc'h G, Cornet M. Borréliose de Lyme : situation générale et conséquences de l'introduction en île-de-France d'un nouvel hôte, le tamia de Sibérie. [Lyme borreliosis: general situation and consequences of the introduction of a new host in Ile-de-France, the Siberian chipmunk]. French. Bulletin épidémiologique hebdomadaire. 14 Sept 2010. French. Available from: http://www.invs.sante.fr/ beh/2010/hs/beh_hs.pdf

13. Flahault A, Blanchon T, Dorleans Y, Toubiana L, Vibert JF, Valleron AJ. Virtual surveillance of communicable diseases: a 20-year experience in France. Stat Methods Med Res. 2006;15(5):413-21.

14. Chauvin P, Valleron AJ. Attitude of French general practitioners to the public health surveillance of communicable diseases. Int J Epidemiol. 1995;24(2):435-40. http://dx.doi.org/10.1093/ije/24.2.435

15. Stanek G, Fingerle V, Hunfeld KP, Jaulhac B, Kaiser R, Krause A, et al. Lyme borreliosis: clinical case definitions for diagnosis and management in Europe. Clin Microbiol Infect. 2011;17(1):69-79.

http://dx.doi.org/10.1111/j.1469-0691.2010.03175.x 
16. Wormser GP, Dattwyler RJ, Shapiro ED, Halperin JJ, Steere AC, Klempner MS, et al. The clinical assessment, treatment, and prevention of lyme disease, human granulocytic anaplasmosis, and babesiosis: clinical practice guidelines by the Infectious Diseases Society of America. Clin Infect Dis. 2006;43(9):1089134 .

http://dx.doi.org/10.1086/508667

17. Réseau Sentinelles. [Sentinelles network]. Estimation des incidences à partir des données de médecine de ville du réseau Sentinelles. [Incidence estimate based on GP data in the Sentinelles network]. Paris: Réseau Sentinelles; 2010. French. Available from: http://www.sentiweb.fr/1384.pdf

18. Évolution et structure de la population. [Population structure and its evolution]. Paris: National Institute of Statistics and Economic Studies (INSEE); 2012. French. Available from: http:// www.insee.fr/fr/themes/theme.asp?theme $=2 \&$ sous_theme $=1$

19. Programme de Médicalisation des Systèmes d'Information (PMSI). Lyon: Agence technique de l'information sur l'hospitalisation; 2012. Available from: https://www.epmsi. atih.sante.fr/

20. World Health Organization (WHO). International statistical classification of diseases and related health problems. 10th Revision. Volume 2. Instruction manual. 2010 ed. Geneva: WHO; 2011. Available from: http://www.who.int/ classifications/icd/ICD10Volume2_en_2010.pdf

21. Altpeter E, Zimmermann H, Oberreich J, Péter O, Dvorák C and the Swiss Sentinel Surveillance Network. Tick related diseases in Switzerland, 2008 to 2011. Swiss Med Wkly. 2013;143:W13725.

22. Vanthomme K, Bossuyt N, Boffin N, Van Casteren V. Incidence and management of presumption of Lyme borreliosis in Belgium: recent data from the sentinel network of general practitioners. Eur J Clin Microbiol Infect Dis. 2012;31(9):238590. http://dx.doi.org/10.1007/s10096-012-1580-3

23. Ertel SH, Nelson RS, Cartter ML. Effect of surveillance method on reported characteristics of Lyme disease, Connecticut, 1996-2007. Emerg Infect Dis. 2012;18(2):242-7. http://dx.doi.org/10.3201/eid1802.101219

24. Dubrey SW, Bhatia A, Woodham S, Rakowicz W. Lyme disease in the United Kingdom. Postgrad Med J. 2014;90(1059):33-42 http://dx.doi.org/10.1136/postgradmedj-2012-131522

25. Gray JS, Dautel H, Estrada-Pena A, Kahl O, Lindgren E. Effects of climate change on ticks and tick-borne diseases in europe. Interdiscip Perspect Infect Dis. 2009;2009:593232.

26. Subak S. Effects of climate on variability in Lyme disease incidence in the northeastern United States. Am J Epidemiol. 2003;157(6):531-8. http://dx.doi.org/10.1093/aje/kwg014

27. Keesing F, Belden LK, Daszak P, Dobson A, Harvell CD, Holt RD, et al. Impacts of biodiversity on the emergence and transmission of infectious diseases. Nature. 2010;468(7324):647-52. http://dx.doi.org/10.1038/natureo9575

28. Mehnert WH, Krause G. Surveillance of Lyme borreliosis in Germany, 2002 and 2003. Euro Surveill. 2005;10(4):pii=531.

29. Wilking H, Stark K. Trends in surveillance data of human Lyme borreliosis from six federal states in eastern Germany, 20092012. Ticks Tick Borne Dis. 2014;5(3):219-24. http://dx.doi.org/10.1016/j.ttbdis.2013.10.010

30. Lipsker D, Lieber-Mbomeyo A, Hedelin G. How accurate is a clinical diagnosis of erythema chronicum migrans? Prospective study comparing the diagnostic accuracy of general practitioners and dermatologists in an area where lyme borreliosis is endemic. Arch Dermatol. 2004;140(5):620-1. http://dx.doi.org/10.1001/archderm.140.5.620

31. Bennet L, Stjernberg L, Berglund J. Effect of gender on clinical and epidemiologic features of Lyme borreliosis. Vector Borne Zoonotic Dis. 2007;7(1):34-41.http://dx.doi.org/10.1089/ vbz.2006.0533

32. Gueorguiev Penev D, Laurent E, Baron S, Diot E, Bastides F, de Gialluly C, et al. [Lyme borreliosis: census of adult patients hospitalized in Indre-et-Loire (France), from the Hospital Discharge Data (1999-2006)]. Rev Epidemiol Sante Publique. 2010;58(5):339-47. French. http://dx.doi.org/10.1016/j.respe.2010.05.003 